Instructions for authors, subscriptions and further details:

http://generos.hipatiapress.com

\title{
A Thematic Analysis of Sexist Bollywood Songs
}

Nasrina Siddiqi ${ }^{1}$

1) University of Delhi

Date of publication: June 25th, 2020

Edition period: June-October 2020

To cite this article: Siddiqi, N. (2020). A Thematic Analysis of Sexist Bollywood Songs. Multidisciplinary Journal of Gender Studies, 9(2), 111136. doi: $10.17583 /$ generos. 2020.4628

To link this article: http://dx.doi.org/10.17583/generos.2020.4628

\section{PLEASE SCROLL DOWN FOR ARTICLE}

The terms and conditions of use are related to the Open Journal System and to Creative Commons Attribution License (CC-BY). 


\title{
A Thematic Analysis of Sexist Bollywood Songs
}

\author{
Nasrina Siddiqi \\ University of Delhi
}

\begin{abstract}
Music reflects the socio-cultural configuration of a society at a given point of time. With proven effects of music on mental and physical health, researchers have now started studying it as a therapeutic technique. While listening to songs can cure stress and many other psychological infirmities, inappropriate lyrical content can impact listeners' attitudes and behaviors negatively. Studies have so far focused on the content structure and implicit elements of lyrics while the probable individual and societal consequences of the same remain less explored and understood. Guided by this objective, the present study is an attempt to explore how sexist lyrics can be instrumental in propagating regressive patriarchal values and sexism. The investigation involves Thematic Analysis of nine Bollywood songs, with explicitly sexist lyrics, chosen through purposive sampling technique. Results reveal that sexist lyrics may be contributory in increasing audience's tolerance for sexism by creating a power imbalance between the two sexes, normalizing objectification, misogyny and stalking and fostering gender stereotypes. Implications of the study are duly discussed.
\end{abstract}

Keywords: beauty-status exchange theory; bollywood songs; sexist lyrics; sexual economics; sociology of music; thematic analysis. 


\title{
Un análisis temático de las canciones sexistas de Bollywood
}

\author{
Nasrina Siddiqi \\ University of Delhi
}

\section{Resumen}

La música refleja la configuración sociocultural de una sociedad en un momento dado. Con efectos probados de la música en la salud mental y física, los investigadores han empezado a estudiarla como una técnica terapéutica. Mientras que escuchar canciones puede curar el estrés y muchas otras enfermedades psicológicas, el contenido lírico inapropiado puede impactar negativamente en las actitudes y comportamientos de los oyentes. Los estudios se han centrado hasta ahora en la estructura del contenido y los elementos implícitos de las letras, mientras que las probables consecuencias individuales y sociales de las mismas siguen siendo menos exploradas y comprendidas. Guiados por este objetivo, el presente estudio es un intento de explorar cómo las letras sexistas pueden ser instrumentales en la propagación de los valores patriarcales regresivos y el sexismo. La investigación comprende el análisis temático de nueve canciones de Bollywood, con letras explícitamente sexistas, elegidas mediante una técnica de muestreo intencional. Los resultados revelan que las letras sexistas pueden contribuir a aumentar la tolerancia del público hacia el sexismo creando un desequilibrio de poder entre los dos sexos, normalizando la objetivación, la misoginia y el acecho y fomentando los estereotipos de género. Se examinan debidamente las consecuencias del estudio.

Palabras clave: teoría del intercambio de estados de belleza; canciones de Bollywood; letras sexistas; economía sexual; sociología de la música; análisis temáticos. 


\section{Siddiqi - A Thematic Analysis of Sexist Bollywood Songs}

$\mathbf{M}$ usic can be seen as a powerful tool to study the socio-cultural makeup of a society. From social customs and values to people's attitudes, a song can tell us virtually everything about the structure of a society at a given point of time (Rogers, 2013). Previous researches indicate that exposure to violent music creates acceptance for hostile cognition (Johnson, Jackson \& Gatto, 1995; Anderson, Carnagey \& Eubanks, 2003). Similarly, songs that glorify the sexual subordination of women have been found to cultivate a sense of acceptance for teen dating violence, among women (Johnson, Adams, Ashburn \& Reed, 1995). Likewise, Objectification theory (Fredrickson \& Roberts, 1997) explains internalized self-objectification among women as a result of recurrent sexual objectification of their bodies by the media.

In their research, Frisby and Behm-Morawitz (2019) asserted that media messages influence peoples' "perceptions of appropriate gender-based conduct, normative gender roles, self-evaluative gender-specific standards, and self-efficacy beliefs" (p. 2). Consistent with this view, Fischer and Greitemeyer (2006) discovered that stereotypical sex role behavior is an outcome of exposure to violent music videos, while Johnson, Jackson and Gatto (1995) found that acceptance of gendered violence is increased by exposure to misogynistic songs. Furthermore, frequent exposure to violent media content has been found to make audience desensitized to such violence (Rosenberry \& Vicker, 2009) while exposure to misogynistic songs has surfaced as a determinant of listeners' attitude towards domestic violence (Cundiff, 2013). Peoples' sexual cognitions are also found to be influenced by the presence of sexual content in music lyrics (Nowotny, 2016). Additionally, Greitemeyer (2009) empirically established that people exposed to sexist music are more likely to engage in sexually aggressive behavior than those who are not exposed to it because lyrics imbued in misogyny and sexism create a fallacious cultural view of masculinity, which is essentially characterized by aggression and violence (Wood, 2012).

Hence, sexist music has 'real-world effects' (Weitzer \& Kubrin, 2009) in that it fosters gendered socialization and gives rise to gender inequality (Martino et al. 2006). The studies discussed above suggest that music subliminally impacts our attitudes, thought process and behaviors (Lull, 1985) and, therefore, it has a strong bearing on the collective cognition and behavior of any given society. 
Hence, music and songs should be viewed not merely as art forms to be enjoyed but also as reverberations of socio-cultural rhythms (Cook, 1998). The relationship between local culture and songs is bilateral in that existing cultural norms and rhetoric determine lyrical themes at a specific spatiotemporal point while lingual and emotive contents of songs, on the other hand, strongly shape people's attitudes, perspectives, behaviors and eventually influence collective culture.

Various media effect approaches attest this view and theorize that the relationship between media content and audience's attitude is similar to a causal relationship (Ferreira, 2014). Extrapolating from this proposition, the rise in sexual violence, such as rape and acid attacks, in India can be attributed to sexist media content, including sexist songs.

As per statistical data India recorded 106 reported cases of rape in 2016 (The Quint, 2018), more than 500 cases of acid attack in 2015 (Islam, 2016) and 259 registered cases of stalking in the first six months of 2017 (Gender Matters, 2018). The current study seeks to locate the role of sexist lyrics in explaining such gendered violence and the underlying sexism prevalent in Indian society.

Put simply, the present research intends to explore the possible societal consequences of frequent exposure to sexist lyrics. While plenty of research studies have already looked at the components of sexist lyrics (Rogers, 2013; Neff, 2014; Odhiambo, 2015), the current investigation is one of its kind in that it goes a step further and explores how exposure to sexist lyrics can be instrumental in the formation of sexist attitudes, cognitions and behaviors. Leading Music sociologist Simon Frith (2011), in his essay on music and identity, highlights the importance of 'trace[ing] the connections back, from the work (the score, the song, the beat) to the social groups who produce and consume it'. In alignment with Frith's idea, the study looks at how music as a constituent of our social structure resonates with the larger socio-cultural whole (what sociologist call 'homology'), and how this synchronized relationship affects collective attitudes.

\section{Theoretical Positioning}

The study is located within the broader framework of Sociology of Music (Music sociology), which has its roots in the seminal works of leading sociologists such as Max Weber, Howard Becker and Pierre Bourdieu, to 


\section{Siddiqi - A Thematic Analysis of Sexist Bollywood Songs}

name a few. Sociology of Music delineates music as a sociological construct that is closely intertwined with culture, politics and social stratification. From this vantage point, music not only reflects existing power equations across different social strata but it also plays an important role in creating collective identities, shaping attitudes and changing societal norms.

According to Dowd (2007), '[music can be closely related to issues such as] subcultures, the reproduction of inequality, globalization, identity formation, and social movements'. Adopting this framework, the current study explores the potential socio-cultural consequences of sexist lyrics. Therefore, the present research is also grounded in critical scholarship for it seeks to discover how songs, as mass media tools, may widen the gender gap and promulgate gender based power imbalances.

In addition, the study also employs different theories of media effects, viz. unlimited effects theory, passive audience theory and social cognitive approach, to explicate how songs as tools of mass media are important in attitude and behavior formation. While the unlimited effects theory assumes that media is all powerful, the passive audience approach views audience as passive recipients of media content who do not have the autonomy to choose what they consume via media. Likewise, social cognitive approach underscores the role of media in attitude shaping through vicarious learning and reinforcement. As per this approach, observational learning makes audience emulate media content. Moreover, how rewarding a specific behavior is shown through media representations, determines the likelihood of audience imitating it in real life. Together these approaches provide a window to look at the social consequences of sexist music and enable us to put things into perspective.

\section{Method}

\section{Sampling and Data Collection}

Sexist Bollywood songs, procured from youtube.com, constituted the data for the current study. Songs were deemed sexist if they met all or some of the criteria of sexist lyrics, proposed by Rogers (2013). Rogers (2013) conceptualized sexist lyrics as those 'that make reference to women in a way that generalizes, stereotypes, degrades, demoralizes, objectifies, or threatens 
physical or sexual harm' and outlined 9 components that are essentially found in sexist songs. These include:

1. Depiction of women in traditional gender roles

2. Use of words that portray women as inferior

3. Overemphasis on a woman's appearance to determine her worth

4. Use of female pronouns when referring to objects

5. Portrayal of women with negative stereotypes

6. Portrayal of women as sexual objects

7. Referring to women as sex workers

8. Portrayal of forced sexual acts as masculine

9. Glorification of violence against women

While Rogers (2013) approached sexism in a more women centric fashion, which manifests in both her conceptualization and classification of sexist lyrical contents, the current study employs a more gender neutral perspective and defines sexist songs in terms of their gender chauvinistic content. Simply put, the study operationalizes the notion of sexist lyrics as the use of discriminatory language in a song that can be targeted towards both women as well as men. Likewise, the taxonomy of sexist lyrics is borrowed from Rogers but unlike Rogers' categorization that holds a gender skewed view of sexism, this study is guided by the idea that both the genders can be stereotyped and discriminated against through sexist songs.

Based on the aforementioned criteria, 9 Bollywood songs were selected (table-1), using Purposive Sampling Technique. All these songs were released within the timeframe of 2011-2018 and hence the findings are expected to reflect current trends in Bollywood music.

Table 1: Table summarizing the details of selected songs.

\begin{tabular}{clllll}
\hline $\begin{array}{c}\text { Sr. } \\
\text { no. }\end{array}$ & Song & Album/movie & Singer & Lyricist & Year \\
\hline 1 & Na ja na ja & Na ja na ja & Pav Dharia & $\begin{array}{l}\text { Don Jaan, } \\
\text { Manav Sangha }\end{array}$ & 2017 \\
2 & Agal bagal & $\begin{array}{l}\text { Phata poster } \\
\text { nikla hero }\end{array}$ & Mika Singh & $\begin{array}{l}\text { Pritam } \\
\text { Chakraborty }\end{array}$ & 2013 \\
3 & Gandi baat & $\begin{array}{l}\text { R... Rajkumar } \\
\text { Kalpana }\end{array}$ & $\begin{array}{l}\text { Anumam Amod } \\
\text { Patowary, }\end{array}$ & 2013
\end{tabular}


117 Siddiqi - A Thematic Analysis of Sexist Bollywood Songs

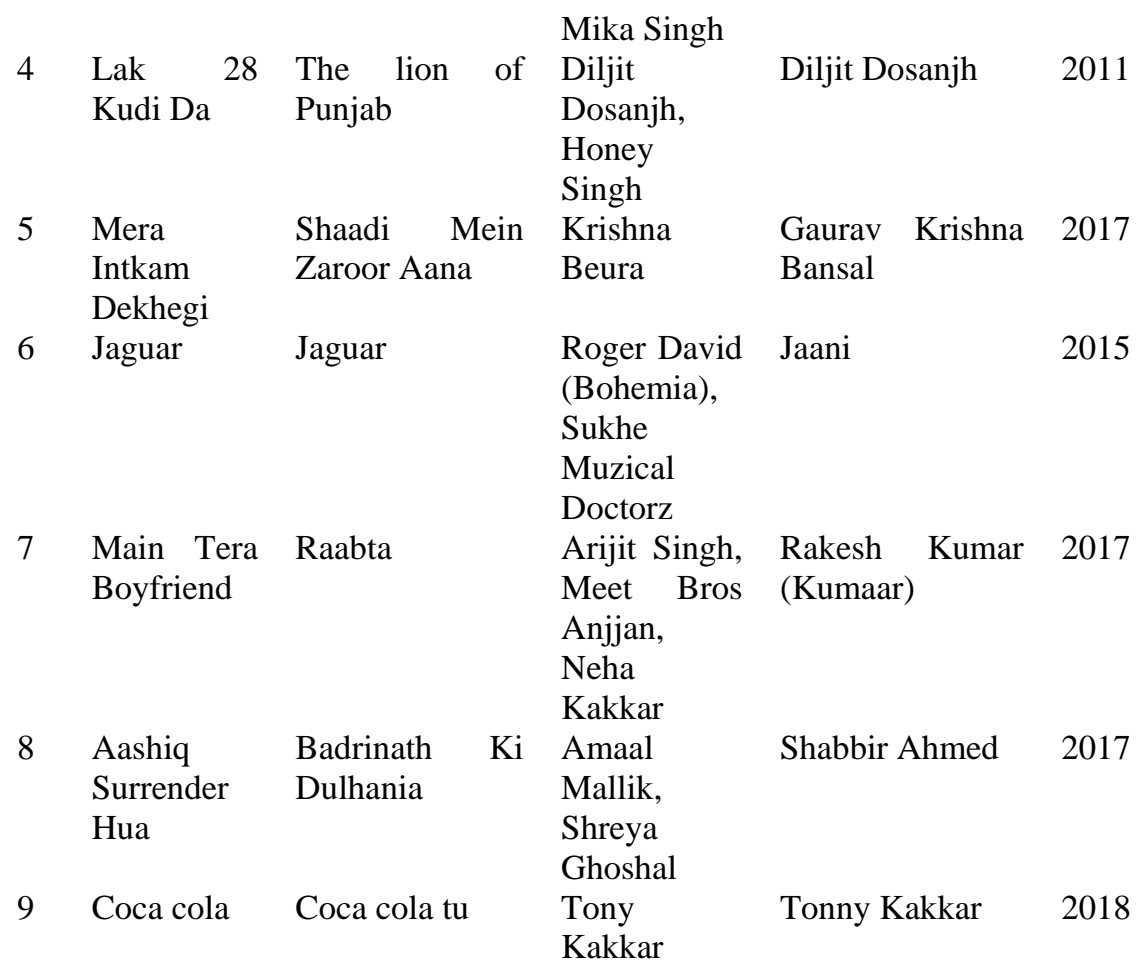

Although popularity was not an inclusion criterion, most of the selected songs were found to be quite popular. Figure- 1 represent their viewership on the basis of the number of views and likes each of these songs received on Youtube.com. 
Figure-1: Graphical depiction of the number of views and likes for each selected song:

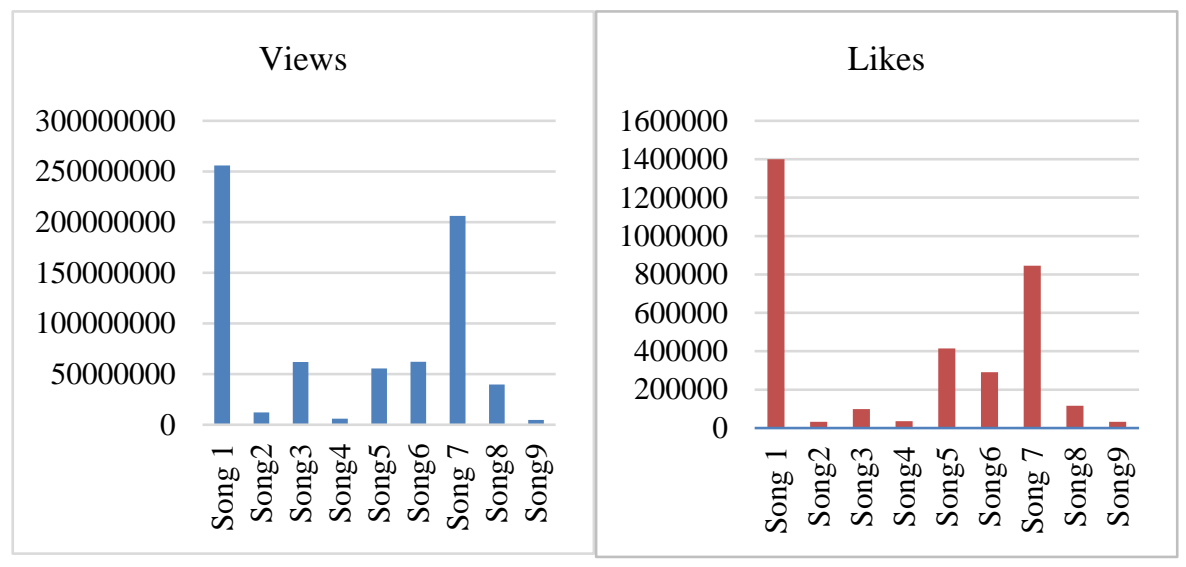

Source: www.youtube.com

Figure-1 explicates that majority of the shortlisted songs are liked by Millions of people and are quite popular among the audience, which implies that these songs may have extremely far-reaching societal implications. It must also be noted here that these statistics are obtained from only one source and hence, the actual popularity of these songs might be greater than what these data indicate.

\section{Technique of Data Analysis}

To analyse selected songs, the current investigation employed thematic analysis, as the objective was to identify common themes that are recurrently found in sexist Bollywood songs. As the name suggests, thematic analysis is a preliminary type of qualitative data analysis technique that adds meaning to raw data by identifying broad themes, therefrom. According to Braun and Clarke (2006) 'thematic analysis should be seen as a foundational method for qualitative analysis'. Whereas some researchers employ it as a technique of data analysis, others are of the opinion that 'thematization' is a common factor across all qualitative researches and hence thematic analysis should be 


\section{Siddiqi - A Thematic Analysis of Sexist Bollywood Songs}

seen as a broader tool used in all qualitative enquiries rather than one individual technique (Boyatzis, 1998).

Moreover, researchers have further bifurcated it into two types; namely small q and big Q thematic analyses (Kidder \& Fine, 1987; Lyons \& Coyle, 2007). Whereas the former refers to use of qualitative thematic analysis within the broader framework of quantitative research, the latter is a form of qualitative thematic analysis that operates within a qualitative paradigm (Kidder \& Fine, 1987). As opposed to small q technique, which involves the use of code book and computation of reliability through statistical methods like Cohen's Kappa etc., big Q thematic analysis emphasizes on contextualized understandings, rejects the idea of objective reality and embraces researcher's subjectivity (Lyons \& Coyle, 2007).

The current study employs big Q thematic analysis and follows a fluid, flexible, organic and iterative coding scheme; which is central to this type of analysis (Lyons \& Coyle, 2007). Moreover, in the current study, themes have been identified only by the researcher and no attempt is made to check inter-rater reliability of the same. This is guided by Lyons and Coyle's (2007) proposal that while using big Q technique, it is not necessarily required to have more than one researchers/coders, because it emphasizes on accepting rather than eliminating researcher's subjectivity.

\section{Procedure}

After sampling sexist songs, Braun and Clarke's (2013) six-step process was followed to identify emergent themes. These steps include:

1. Data familiarization. To begin with, each song was heard repeatedly and the lyrics were noted down. To ensure accuracy, transcribed lyrics were compared with those available on websites such as glamsham.com and lyricsbell.com etc. These transcribed lyrics were read repeatedly in order to identify emergent themes.

2. Generating initial codes. After listening to songs and going through the transcripts repeatedly, each verse was analyzed, both, separately as well as in the wider context of the song and any surfacing theme was jotted down. This process resulted in a number of key words (initial codes). After a careful analysis of initial codes, similar and inter-related keywords were clustered to create corresponding sub-themes. According 
to Braun and Clarke (2013) a sub theme shares a central organizing concept with a theme but highlights one particular aspect of it. So the next step was to identify broader themes that could encompass all emergent subthemes.

3. Search for themes. At this stage similar or interrelated subthemes were grouped together to create wider, overarching themes. A theme captures something important about the data in relation to the research question, and represents some level of patterned response or meaning within the data set (Braun \& Clarke, 2103). Theme identification is the highest level of abstraction in thematic analysis as these themes provide a bird's eye view of the data. Search for themes eventually resulted in four major themes viz. Glorification of unrequited love, Misogyny, Stereotypical representation and Differential criteria for judging men and women.

4. Reviewing themes. After the major themes were identified, all the initial keywords and subthemes were checked again for possible inclusion. Moreover, at this stage certain subthemes were dropped from the final list either because they did not appear consistently in all the songs or because they could not fit in any of the surfacing themes. The process of thematic mapping (Braun \& Clarke, 2103) was applied to understand the patterns of relationships across different themes and sub-themes. Thematic mapping involves the identification of horizontal (across themes) as well as vertical (between themes and sub-themes) relationships. This helps ensure that each subtheme is put under the most appropriate theme and that there is no overlap. Thematic mapping is extremely important as it helps represent data (themes/subthemes) in meaningful and coherent ways rather than just creating mutually unrelated chunks of data.

5. Defining themes. Once all the major themes were identified and reviewed, they were operationally defined as to how they represent their constituent subthemes. Defining themes is paramount in that it enables readers to understand the association between subthemes and themes and gives a clear idea about the process that guides data analysis.

6. Discussion. The last stage involved a detailed discussion of all the emergent themes in light of existing research and theoretical frameworks. 


\section{Siddiqi - A Thematic Analysis of Sexist Bollywood Songs}

\section{Findings and Discussion}

Analysis of the selected songs yielded four overarching themes which have been operationally defined as follows:

- Glorification of unrequited love. Showing one-sided love as heroic and justifying acts like stalking in the name of perseverant love. This theme also involves a false belief that 'No' implicitly means 'Yes' and denial of rejection or disinterest which, at time, also warrants feelings of vengeance from one's love interest.

- Misogyny. Misogyny is an umbrella term used to denote the feelings of hatred and contempt for women (Ruth, 1990) which can be manifested in numerous forms. In this particular study three subthemes have been categorized as misogynistic, which include; Condescending attitude towards 'feminine roles' i.e. belittling tasks which have conventionally been described as 'feminine', Objectification of women's bodies and painting them as sexual objects or commodities to be consumed by men and Blaming women for 'inviting' men or holding women responsible for unwanted attention and sometimes, even stalking.

- Stereotypical representation. The next theme includes representation of both men and women in stereotypical fashion and creating unrealistic generalizations.

- Differential criteria for judging men and women. The final theme encapsulates shades of discrimination, particularly with regard to judgments about the desirability of men and women.

Table 2: Table depicting major themes and subthemes.

\section{Major themes Sub themes Excerpts from lyrics (with translation)}

Inability to

accept rejection

or disinterest
Tere kolon haan kara ke chadni (I would not give up until I make you say yes)

Tu ne English me jab humko danta to ashiq surrender hua. (When you scolded me in English, your lover surrendered) 
Tu ne bhav nhi diya re. (You did not give me any importance)

False belief that

'No' means

'Yes'

Stalking

Glorification of unrequited love
Mainu Bhi pasand tu karti zarur (I am sure you like me too)

Main tera boy friend tu meri girl friend Tu mainu kehendi na na ( I am your boyfriend, you are my girlfriend but you keep saying no to me)

Tera picha krun to rokne ka nhi (Don't stop me if I stalk you)

Tera rasta jo rokun tokne ka nhi (Don't interrupt when I block your way)

Beedi peeke nukkad pe wait tera kiya re (I waited for you on the corner, smoking cigarettes)

Ruk te ja meri gal te sun le, o mainu kehendi na na na na ([I ask her to] stop and listen to me but she keeps saying no)

Revenge thukra ke mera pyar mera inteqam dekhegi (Now that you have discarded my love, you will see my revenge)

Duniya shikast teri sare aam dekhegi (The world will see your defeat)
Condescension towards

'feminine roles'
Rotian pakain nal mere gane gayin (You will spend rest of your life making breads and will sing my songs [being remorseful for rejecting me])

Body butter cream (Your body is like 


\section{Siddiqi - A Thematic Analysis of Sexist Bollywood Songs}

Misogyny Objectification buttercream)

Thande ki bottle...tujhe ghat ghat main pee lun (You are a cold drink, I will gulp you))

Blaming women Neeli neeli ankhiyon me Dilli wala kajra, for 'inviting' men mainu invite kerda (Delhi's kohl in your blue eyes invites me)

Portraying

Nakhra high rate kudi da (Her tantrums women as are high-fi) tantrum throwers

Stereotypical representation
Depicting women as materialistic

Portraying men as idle stalkers
Att tera nakhra tera hi kusoor (Your tantrum is none of your fault)

Kudi kendi pehle Jaguar Le lo, fir jinna marzi pyar lelo (My girlfriend says first buy me a jaguar [luxury car], then take as much love from ,me as you want)

Beedi peeke nukkad pe wait tera kiya re, Khali peeli 18 cup chai bhi to piya re (I waited for you on the corner, smoking cigarettes and drank 18 cups of tea for no reason)

Main vella baitha derda (I sit aimlessly)

Focus on

Lak 28 kudi da, 47 weight kudi da (The

physical

Differential appearance of criteria for judging men women girl's waist is 28 and her weight is 47)

Dikhne me thi tu kadak (You looked hot)

Sohni model lagdi (She looks like a beautiful model)

Moti da vyah hogya (Even the corpulent 
girl got married)

Teri jaisi beauty kisi ki bhi nhi honi (I have never seen anyone as beautiful as you)

Depicting money Take you to Paris, Take you to London as a major

determinant of (As) long as you (are) with me, you will men's live in abundance

desirability

The first theme (Table-2) emerging from the data was glorification of unrequited love or portraying one-sided love as heroic. This theme appeared in almost all the sampled songs, in different forms. Interestingly, in all these songs men were portrayed as one-sided lovers, with their supposed love interests being completely uninterested and unwilling to reciprocate their feelings.

A careful analysis of selected songs revealed that unacceptance of rejection or disinterest is recurrently portrayed as 'Masculine' and 'Macho'. There were numerous verses that highlighted the supposed 'heroism' in trying to persuade a woman despite her explicit disinterest and rejection. Not only do these songs applaud denial of rejection but also construe refusal as a challenge for a stubborn one-sided lover to become more determined to 'achieve his object of desire'. This is evident in verses like 'Tu ne English me jab humko danta to ashiq surrender hua' (When you scolded me in English, your lover surrendered) and 'Tere kolon haan kara ke chadni' (I would not give up until I make you say yes).

The sub-theme also resonates with the notion of male entitlement; a patriarchal bias deeply embedded in Indian culture (Kumar, Gupta \& Abraham, 2002). The preponderance of this theme reflects that being rejected by a woman is culturally viewed as a threat to one's manliness and that real men are expected to resist rejection instead of accepting it. Such beliefs are byproducts of centuries old patriarchal values that are responsible for sustaining and fostering toxic masculinity. 


\section{Siddiqi - A Thematic Analysis of Sexist Bollywood Songs}

Being closely related to unacceptance of rejection, the next subtheme goes to a whole new level of denial and infers rejection as a gesture of implicit love. The idea that 'No' actually means 'Yes' manifests in verses like; 'Mainu Bhi pasand tu karti zarur' (I am sure you also like me). This theme too was continuously found across most of the selected songs and seemed to have normalized the idea that rejection, particularly coming from a woman, should rather be viewed as a sign of unexpressed love. What is more distressing is the way these songs strengthen this false assumption and depict rejection as a 'strategy' that women often employ to test the sincerity and tenacity of their lover. The Dis-inhibitory effect in Bandura's (2001) social cognitive theory describes that representing a forbidden behavior as rewarding through media enhances its possibility of being learned and expressed by the audience. Hence, each time a Bollywood song shows a heroin falling for the hero after her initial rejection and succumbing to his perseverance (which in most cases involves stalking), it reinforces the misconception that 'no means yes' and increases the proclivity of "romantic denial” among audience.

While the first two subthemes are at the level of thought, remaining two are more action-based or behavioral. In fact, the following subthemes namely; stalking and revenge, can be seen as originating or resulting from the first two subthemes. Denying rejection and inferring it as unexpressed love eventually justifies acts like stalking. When a one-sided lover is convinced that rejection is actually affection in disguise, he rationalizes stalking as an attempt to unleash the hidden love. Furthermore, verses like 'Tera picha krun to rokne ka nhi' (Don't stop me if I follow you) and 'Tera rasta jo rokun tokne ka nhi' (Don't interrupt me if I block your way) not only justify stalking but also instill a sense that if required, the lover can rightfully stalk his supposed 'beloved'.

Finally, the last subtheme i.e. revenge, is the most precarious form of one-sided love. Whereas stalking itself is a violation of privacy, it can take a more gory form if coupled with feelings of vengeance for being rejected. The presence of this theme in mainstream Bollywood songs like 'thukra ke mera pyar mera inteqam dekhegi' (Now that you have discarded my love, you will see my revenge) is both dreadful and alarming as it can encourage audience to seek revenge by physically or emotionally harming their love interest. This can be better understood using Bandura’s (2001) Cognitive 
Theory of Social Communication which explains the role of vicarious or observational learning in acquiring new behaviors from media. As per this approach, audience mimic or imitate the behavior that is shown in media. Thus glorified portrayal of revenge in mainstream Bollywood songs can instigate people to indulge in vengeful behavior and to even commit heinous acts like threatening, stalking, acid attacks and rape etc.

If we further look at all these subthemes from the framework of music sociology, we get deeper insights into the vitality of songs and music in the construction of social realities. Lyrical rhetoric, as per this approach, strongly impact the collective identity of a socio-cultural cohort by molding attitudes and creating power equations.

Likewise, the Unlimited Effect Theory postulates that media holds absolute power over the masses and influences people in a way that closely resembles “Causal relationship” (Santos, 1992). Ferreira (2014:2) puts it like this:

...the audience, taken over by the media, was seen as atoms of individuals clustered in a uniform mass and, when exposed to cultural goods, reacted the same way, as in a causal relation between exposition and action.

Hence, songs as “cultural goods” possess the ability to mobilize audience's attitudes and subsequent behaviors. The present analysis advocates the same idea and explains gender-based power hierarchies that exist in all sociocultural domains as a by-product of discriminatory and sexist lyrical content.

Emergent themes clearly elucidate how the notion of romantic love or Eros (Lewis, 1960) becomes culturally gendered through sexist songs. Such lyrics portray love not as the pursuit of affection and companionship but as a challenge to control and overpower women who reject men.

Therefore, glorification of unrequited love can potentially create a culture where women's individuality and power is intimidated by romanticizing acts like stalking and a power equation is created which prioritizes men's desires over women's decisions about their own lives.

Misogyny or hatred towards women emerged as the second major theme (Table-2). Analysis revealed that selected sexist songs contained elements of misogyny in different forms. There were verses like 'Rotian pakain nal mere gane gayin' ([if you say no to me] you will [spend your 


\section{Siddiqi - A Thematic Analysis of Sexist Bollywood Songs}

life] making rotis [bread] and will sing my songs) that belittled and disparaged feminine roles. The fact that making rotis is portrayed as a sign of living a disdainful life sheds light on how roles that are traditionally assigned to women are strategically typecast as 'secondary' and less meaningful, to maintain male dominance. Such condescension and chauvinism is problematic for it strengthens patriarchal values, helps in sustaining gender based segregation of roles and responsibilities and creates gender disparity by offering more power and prerogatives to men.

Misogyny was also evident in the form of women's objectification. There were several instances where women were described as inanimate objects and their existence was reduced to being possessed by men. Famous song lyrics like 'Body butter cream' ([Your] body is [like] butter cream) and 'Thande ki bottle...tujhe ghat ghat main pee lun' (You are a cold drink.... I will gulp you) indicate the ubiquitous acceptance of women's objectification and how it easily makes its way to a global audience through popular Bollywood chartbusters.

Blaming women for 'inviting' men surfaced as the third subtheme under misogyny wherein women were represented as instigating men to stalk them. In verses like 'Neeli neeli ankhiyon me Dilli wala kajra, mainu invite kerda' (Delhi's kohl in your blue eyes invites me), the bold usage of the term 'Invite' creates a sense that women should be blamed if they get stalked while men have the liberty to conveniently shrug off their responsibility.

These kinds of lyrics not only normalize acts like stalking but also endorse victim blaming, which is another repulsive form of misogyny. This can be explained in the light of Passive audience theory of media effects which proposes that audience have no options to choose from, when it comes to media content and hence they end up consuming whatever the industry is producing, totally "acritically" (Wolf, 1995). Congruent with this view, songs can be viewed as powerful catalysts in attitude formation whose content the audience do not get to choose critically and rationally. Hence, whatever is fed to the masses through songs gets accepted at the macro scale with absolutely no filter or critique. This explains why the sexism and decadence expressed in these songs becomes "mainstream" and influences the overt behavior of the uncritical, passive audience. The finding further chimes with Ballard and Coates' (1995) opinion that misogynistic lyrical 
themes condone and foster misogynistic behavior and attitudes (Ballard \& Coates, 1995).

The third surfacing theme was Stereotypical representation (Table-2), which indicated the power of songs in creating and reinforcing stereotypes. Analysis indicated that sexist songs often have gender stereotypes incorporated in their lyrics and make undue generalizations about men and women, which acts as a cultural catalyst in widening the existing gender gap. While delineating the role of songs in creating gender gap and consequent disparity, Rogers (2013) asserted that, 'If people are often confronted by the media and told throughout daily life that the sexes are so different, then it is easy to believe that the differences are real and lead to inevitable inequality.' This can further be explained through Tajfel's (1971) Social Identity approach, which postulates that during the process of social comparison people are under the influence of a cognitive bias called Outgroup Over Generalization which makes them believe that all members of an outgroup are alike, particularly in terms of their negative attributes. And when sexist songs negatively stereotype a specific gender, outgroup over generalization bias becomes more prominent and gender typecasts gain more social credibility, which eventually broadens gender gap.

Thematic analysis indicated that in many of the selected songs women were stereotyped as tantrum throwers so much so that even their rejection was portrayed as 'just another tantrum'. Moreover, verses like 'Nakhra high rate kudi da' (Her tantrums are high-fi) and 'Att tera nakhra tera ki kusoor' (Your tantrum is none of your fault) describe 'nakhra' (tantrum) as a defining characteristic of a woman and paint a flawed and unrealistic picture of femininity.

Additionally, women were also described as greedy and materialistic in songs like 'Kudi kendi pehle Jaguar Le lo' (Girl says first buy me a Jaguar). Such lyrics depict women as manipulators who trap men only for materialistic gains whereas men are portrayed as true lovers who are willing to sacrifice all their possessions to please their beloved.

This, however, is not to say that sexist songs only stereotype women. While such songs frequently subject women to negative stereotypes, they concurrently project men as idle beings who have nothing better to do than stalking and irking women who are not romantically interested in them, which is clearly evident in verses like 'Beedi peeke nukkad pe wait tera kiya 


\section{Siddiqi - A Thematic Analysis of Sexist Bollywood Songs}

re' (I smoked cigarette and waited for you at the corner). Although sexist songs try to project stalking as romantic and macho, it does not change the fact that they stereotype all men and depict masculinity in a negative light, which is equally sexist.

Such gender based stereotyping can be detrimental for the society because frequent exposure to this kind of content can lead to stereotype priming, or the activation of related stereotypes (Cobb \& Boettcher, 2007), which may subsequently produce negative overt behaviors like gender discrimination and gender based aggression etc. Moreover mainstreaming sexism can also result in the internalization of stereotypes. This assertion can be supported with Althusser's (1971) Interpellation hypothesis, which proposes that when a group is continuously stereotyped and labeled, its members begin to internalize those stereotypes and end up becoming what they are labeled as. Thus, propagation of negative gender stereotypes can bring along negative behavioral changes too. Hence, songs that stereotype people on the basis of their gender are blameworthy, to a great extent, for persistently widening gender gap and creating a culture that operates on gender heuristics.

Finally, discrimination, with regard to the parameters used to evaluate the desirability of men and women, also emerged as a significant theme (Table-2). Sexist lyrics often described physical beauty or outward appearance as a key determinant of women's desirability while money or financial status was described as a measure of how desirable a man is. This is evident in verses like 'Sohni model lagdi' ([She] looks like a beautiful model) and '(As) long as you (are) with me, you will live in abundance'.

This is consistent with Sexual Economics theory (Baumeister \& Vohs, 2004) which explains such differentiation as a result of women exchanging their sexuality for men's power and status. According to this approach, sexual partnerships (marriage or otherwise) exist in a 'marketplace' like setting where men are the 'buyers' and women are the 'sellers' (Baumeister, Reynolds, Winegarda \& Vohs, 2017). The framework deems women as sellers because empirical evidence suggests that men demand sex more than women (Baumeister, Catanese \& Vohs, 2001) and according to the Principle of Least Interested, the person who demands something is less powerful than the one who demands it less and that the latter leverages this power to decide the conditions of sharing the desired resource; in this case, sex. Likewise, 
Beauty-Status Exchange Theory posits that men with higher status marry beautiful and physically attractive women (Elder, 1969; Taylor \& Glenn, 1976) in order to complement each other.

However, from a feministic point of view, such differentiations are rooted in the patriarchal configuration of our society, which deliberately describes financial independence and status as masculine responsibilities, in order to maintain male supremacy. Moreover, this kind of differentiation is absolutely unwarranted in contemporary times where most women are as financially independent as men and hence do not require to use their sexuality to attain financial security.

Hence, propagation of such gendered criteria of desirability not only disregards the fact that women hold an equal status in society but also fosters the proliferation of gender differences. Moreover, such differentiations are problematic because over-emphasis on physical beauty and creation of unrealistic beauty standards can produce body image issues (Richins, 1991) which may consequently deflate women's self-esteem and confidence (Grabe \& Ward, 2008). Similarly, highlighting money as the only determinant of men's attractiveness can misguide our country's youth by disseminating the false message that character, values, morality, intelligence and other individual traits are not important for a man, to be desirable.

\section{Conclusion}

The current study was carried out with the objective of exploring how sexist lyrics can influence people's attitudes and behaviors. Analysis of 9 sexist Bollywood songs, chosen purposively using Rogers' criteria, revealed that apart from their central theme i.e. sexism these songs have many other components in common. Such songs are likely to glorify and 'protagonise' denial and misinterpretation of rejection while condoning acts like stalking and revenge in the name of love. As per the media effects theory, these kinds of lyrical themes may strengthen the undue sense of entitlement among men by making them perceive rejection as a threat to their masculine privileges. Further, looking through the lens of music sociology, such lyrical themes may create and enhance gender based power imbalance by assigning greater control to men. Moreover, portrayal of such behavior as chivalrous and 


\section{Siddiqi - A Thematic Analysis of Sexist Bollywood Songs}

heroic can be contributory in normalizing acts of violation such as stalking and rape.

Furthermore, misogyny has been found to be embedded in sexist lyrics, which manifests through the condescension of feminine roles, objectification of women's bodies and victim blaming. Findings also highlight the potential role of sexist lyrics in widening gender gap by spreading gender stereotypes and facilitating stereotype internalization. Finally, the current study underscores how the overemphasis on women's physical appearance in sexist songs may lead to body-image issues among young women on the one hand, and sexualize women and portray them as sexual objects that can be possessed by powerful and affluent men, on the other hand. While such representations project a flawed image of women and femininity, they also have been found to typecast men by making undue generalizations about them. Overall, the findings of this study are similar to those of Frisby and Behm-Morawitz (2019) who found themes involving profanity, misogyny, violence and gender role references in popular music genres.

The current study highlights the probable damaging repercussions of sexist songs, which are often underestimated. Taking into account the fact that music strongly influences mass opinion and regulates attitude formation, the study brings the societal threats of sexist songs to the forefront. The current study can be utilized by social scientists and researchers as an empirical bedrock to build further research upon.

Despite its applicability and relevance, the study is limited in many ways. First of all, the sample size is small which curtails its generalizability. Secondly, the songs have not been categorized on the basis of their genres, which could have offered comparative findings. Future researcher can, therefore, extend this study on a larger sample of songs and can draw more insightful inferences by comparing different genres of Bollywood songs.

\section{References}

Althusser, L. (1971). Ideology and ideological state apparatuses. In L. Althusser (Ed.), Lenin and Philosophy and other Essays. New York: Monthly Review Press. ISBN: 10: 1583670394

Anderson, C.A., Carnagey, N.L. \& Eubanks, J. (2003). Exposure to violent media: The effects of songs with violent lyrics on aggressive thoughts 
and feelings. Journal of Personality and Social Psychology, 84, 960971.

Ballard, M. E. \& Coates, S. (1995). The immediate effects of homicidal, suicidal, and nonviolent heavy metal and rap songs on the moods of college students. Youth and Society, 27, 148-168.

Bandura, A. (2001). Social Cognitive Theory of Mass Communication. In J. Bryant \& D. Zillmann, (Eds.). Media Effects: Advances in Theory and Research. $2^{\text {nd }}$ Ed. (pp. 121-153). Hillsdale: Lawrence Erlbaum.

Baumeister, R. F. \& Vohs, K. D. (2004). Sexual economics: Sex as female resource for social exchange in heterosexual interactions. Personality and Social Psychology Review, 8(4), 339-363. doi: http://journals.sagepub.com/doi/abs/10.1207/s15327957pspr0804_2

Baumeister, R. F., Catanese, K. R. \& Vohs, K. D. (2001). Is there a gender difference in strength of sex drive? Theoretical views, conceptual distinctions, and a review of relevant evidence. Personality and Social Psychology Review, 5, 242-273. doi: http://journals.sagepub.com/doi/abs/10.1207/s15327957pspr0503_5

Baumeister, R. F., Reynolds, T., Winegarda, B. \& Vohs, K. D. (2017). Competing for love: Applying sexual economics theory to mating contests. Journal of Economic Psychology, 63, 230-241. doi: https://doi.org/10.1016/j.joep.2017.07.009

Boyatzis, R. E. (1998). Transforming Qualitative information: Thematic Analysis and Code Development. Thousand Oaks, CA: Sage Publications. ISBN: 0-7619-0960-5

Braun, V. \& Clarke, V. (2006). Using thematic analysis in psychology. Qualitative Research in Psychology, 3(2), 77-101. doi: http://dx.doi.org/10.1191/1478088706qp063oa

Braun, V. \& Clarke, V. (2013). Teaching thematic analysis: Overcoming challenges and developing strategies for effective learning. The Psychologist, 26(2), 120-123. doi: http://eprints.uwe.ac.uk/21155

Cobb, M. D. \& Boettcher, W. A. (2007). Ambivalent sexism and misogynistic rap music: Does exposure to Eminem increase sexism? Journal of Applied Social Psychology, 37(12), 3025-3042. doi: https://doi.org/10.1111/j.1559-1816.2007.00292.x

Cook, N. (1998). Music: A very short introduction. Oxford: Oxford University Press. 


\section{Siddiqi - A Thematic Analysis of Sexist Bollywood Songs}

Cundiff, G. (2013). The influence of rap/hip-hop music: A mixed-method analysis on audience perceptions of misogynistic lyrics and the issue of domestic violence. The Elon Journal of Undergraduate Research in Communications, 4(1), 71-93.

Dowd, T. J. (2007). The Sociology of Music. In C., D. Bryant, \& D., L. Peck (Ed.), 21st Century Sociology: A Reference Handbook (pp. 249-260). Thousand Oaks, CA: Sage Publications.

Elder, G. H. (1969). Appearance and education in marriage mobility. American Sociological Review, 34(4), 519-33. doi: http://www.jstor.org/stable/2091961?seq=1\#page_scan_tab_contents

Ferreira, R. M. C. (2014). Media effects on the audience attitudes and behavior. Matrizes, 8(1), 255-269.

Fischer, P. \& Greitemeyer, T. (2006). Music and aggression: The impact of sexual aggressive song lyrics on aggression-related thoughts, emotions, and behavior toward the same and the opposite sex. Personality and Social Psychology Bulletin, 32(9), 1165-1176. doi:10.1177/0146167206288670

Fredrickson, B. L. \& Roberts, T. A. (1997). Objectification theory: Toward an understanding of women's lived experiences and mental health risks. Psychology of Women Quarterly, 21, 173-206.

Frisby, C. M. \& Behm-Morawitz, E. (2019). Undressing the Words: Prevalence of Profanity, Misogyny, Violence, and Gender Role References in Popular Music from 2006-2016. Media Watch 10(1), 5-21.

Frith, S. (2011). Music and identity. In S. Hall \& P. du Gay (Ed), Questions of cultural identity, (pp. 108-127). UK. Sage Publications Ltd.

Grabe, S. \& Ward, L. M. (2008). The role of the media in body image concerns among women: A meta-analysis of experimental and correlational studies. Psychological Bulletin, 134(3), 460-476.

Ghosh, B. (2012). Globalization and Social Transformation: Yogendra Singh on culture change in contemporary India. In I. Modi (Ed.), Modernization, Globalization and Social Transformation (pp. 242-256). Jaipur: Rawat Publication. ISBN: 978-. 81-316-0507-3

Goswami, G. P. \& Puri, V. T. (1996). India at the cross-roads: Democratic quality in demanding society. New Delhi: Mittal Publications. ISBN: 81-7099-654-6 
Greitemeyer, T. (2009). Effects of songs with prosocial lyrics on prosocial behavior: Further evidence and a mediating mechanism. Personality and Social Psychology Bulletin, 35(11), 1500-1511. doi:10.1177/0146167209341648

India's rape crisis: 106 rapes per day, 4 in 10 victims minors. (2018, April 16). The Quint. https://www.thequint.com/news/india/india-rape-data-106rapes-per-day-4-in-10-victims-minors

Islam, A. (2016, June 8). Why acid attacks are on the rise in India. Made for Minds. https://www.dw.com/en/why-acid-attacks-are-on-the-rise-inindia/a-19313750

Johnson, J. D., Adams, M. S., Ashburn, L. \& Reed, W. (1995). Differential gender effects of exposure to rap music on African American adolescents' acceptance of teen dating violence. Sex Roles, 33, 597-605.

Johnson, J. D., Jackson, L. A. \& Gatto, L. (1995). Violent attitudes and deferred academic aspirations: Deleterious effects of exposure to rap music. Basic and Applied Social Psychology, 16(1\&2), 27-41.

Kidder, L.H. \& Fine, M. (1987). Qualitative and quantitative methods: when stories coverage. In M. M. Mark \& L. Shotland (eds.), New directions in program evaluation (pp 57-75). San Francisco, CA: Jossey-Bass.

Kumar, S., Gupta, S. D. \& Abraham, G. (2002). Masculinity and violence against women in marriage: An exploratory study in Rajasthan. Domestic Violence in India-Part 4: Men Masculinity and Domestic Violence in India. International Center for Research on Women. https://www.icrw.org/wp-content/uploads/2016/10/Domestic-Violencein-India-4-Men-Masculinity-and-Domestic-Violence-in-India.pdf

Lewis, C. S. (1960). The Four Loves: NY: Harcourt, Brace, Jovanovich. ISBN: 01563293019780156329309

Louise, H. K. \& Fine, M. (1987). Qualitative and quantitative methods: When stories converge. Evaluative Thinking, 1987(35): 57-75. doi: https://doi.org/10.1002/ev.1459

Lull, J. (1985). On the communicative properties of music. Communication Research, 12(3), 363-72.

Lyons, E. \& Coyle, A. (2007). Analysing Qualitative Data in Psychology. London: Sage Publications Ltd. ISBN: 978-1-4129-0782-8 


\section{Siddiqi - A Thematic Analysis of Sexist Bollywood Songs}

Martino, S. C., Collins, R. L., Elliott, M. N., Strachman, A., Kanouse, D. E. \& Berry, S. H. (2006). Exposure to degrading versus non degrading music lyrics and sexual behavior among youth. Pediatrics, 118(2), 430-441.

National Stalking Awareness Month 2018 Begins. (2018, January 2). Gender Matters. http://gendermatters.in/2018/01/national-stalking-awarenessmonth/

Neff, S. (2014). Sexism across musical genres: A comparison (Honors Thesis). Western Michigan University, Michgan, US. Paper 2484

Nowotny, N. (2016). Sexual content in music lyrics and their effects on sexual cognition (Honors in the Major Theses). University of Central Florida, Florida, USA.

Odhiambo, O. J. (2015). Sexual objectification of the woman's body: An analysis of selected popular Benga songs among the Luo community, Kenya. Global Journal of Arts, Humanities and Social Sciences, 3(6), 46-59.

Richins, M. L. (1991). Social comparison and the idealized images of advertising. Journal of Consumer Research, 18(1), 71-83.

Rogers, A. (2013). Sexism in unexpected places: An analysis of country music lyrics. Caravel Undergraduate Research Journal. University of South Carolina.

http://sc.edu/about/offices_and_divisions/research/news_and_pubs/cara vel/archive/2013/2013-caravel-sexism-in-unexpected-places.php

Rosenberry, J. \& Vicker, L. (2009). Applied Mass Communication Theory. A Guide for Media Practitioners. Boston: Pearson Allyn and Bacon.

Ruth, S. (1990). Issues in Feminism: An Introduction to Women's Studies. California, United States: Mayfield Publishing Company. ISBN: 08748493739780874849370

Santos, J. R. (1992). O que é Comunicação. Lisboa: Difusão cultural.

Tajfel, H., Billig, M.G., Bundy, R. P. \& Flament, C. (1971). Social categorization and intergroup behavior. European Journal of Social Psychology, 1(2), 149-178. doi: https://doi.org/10.1002/ejsp.2420010202

Taylor, P. A., \& Glenn, N. D. (1976). The utility of education and attractiveness for females' status attainment through marriage. American Sociological Review, 41(3), 484-98. doi: 
http://www.jstor.org/stable/2094255?origin=crossref\&seq=1\#page_sca n_tab_contents

Weitzer, R. \& Kubrin, C. E. (2009). Misogyny in rap music: A content analysis of prevalence and meanings. Men and Masculinities, 12(1), 3-29.

Wolf, M. (1995). Teorias da comunicação. Tradução de Maria Jorge Vilar de Figueredo. (Ed. 4). Lisboa: Presença.

Wood, J. T. (2012). Gendered Lives: Communication, Gender and Culture $\left(10^{\text {th }}\right.$ Ed.). Boston: Cengage Learning.

Nasrina Siddiqi: University of Delhi, India

E-mail address: nasrina1991faozia@gmail.com 